\title{
Nada substitui uma boa formação humana
}

\author{
Adriana Cláudia Turmina
}

\section{RESUMO}

O presente relato visa recuperar, numa perspectiva geral, o contexto de discussão desenvolvido na 9a JORNATEC em Florianópolis/SC, bem como pretende tecer algumas considerações a respeito da "aventura" que é educar frente à crescente inserção das redes de aprendizagem nas relações pessoais, sociais e profissionais. Por tratar-se de um assunto candente, recuperamos num caráter de síntese, a abordagem discursiva dos palestrantes no decorrer do evento. A partir desses balizamentos, prolongase a importância de se pensar os desafios impostos aos que educam numa sociedade, cuja constância, é a mudança tecnológica.

Palavras-Chave: JORNATEC. Rede de Aprendizagem. Educação.

\section{Situando a estrutura da JORNATEC}

Com perspectivas sempre provocantes, estimulando reflexões críticas a respeito da educação, a 9a edição da Jornada Catarinense de Tecnologia Educacional (JORNATEC), realizada pelo Sistema FECOMÉRCIO Sesc e Senac, em Florianópolis/SC, nos dias 23 a 24 de maio de 2011, trouxe à tona "As redes de aprendizagem e os desafios da educação". Congregando aproximadamente 800 participantes das mais diversas especialidades, dos quais professores, pedagogos, psicólogos, psicopedagogos, gestores e estudantes de universidades, escolas públicas e particulares de todo país, tiveram a oportunidade de assistir conferências e palestras com profissionais renomados na área, tanto em nível nacional, quanto internacional.

Numa perspectiva histórica, voltamos nosso olhar aos anos de 1999, ano da primeira edição da JORNATEC constatando que se passaram mais de uma década e a proposta do referido evento continua firme em seu propósito de desafiar seus participantes a refletir acerca do que representa educar diante de uma 
diversidade de transformações na sociedade. Pensar na atualidade, como as redes sociais se potencializam como redes de aprendizagem, em canais de comunicação, permite aos promotores do evento, provocar reflexões sobre a aprendizagem em novos tempos e espaços.

Nesse intuito, o evento foi estruturado em três perspectivas centrais: Plenária Principal, com conferências de abertura e encerramento, visando congregar as categorias participantes; Jornada para Educadores e Jornada para Gestores, compostas por uma série de palestras primando pela socialização de experiências com o objetivo de fomentar e disseminar a importância das redes de aprendizagem nas instituições educacionais nessas duas vertentes. Há de se realçar a necessidade desses espaços de discussão e reflexão para profissionais da gestão e da educação. Além das palestras, contou-se também, com uma Mesa Temática discutindo aspectos relativos à ética no trabalho docente.

Paralelamente à JORNATEC, aconteceu a 1aㅡ Mostra de Serviços Sesc e Senac, despontando como uma vitrine de serviços do sistema FECOMÉRCIO, a partir de oficinas, minicursos e uma belíssima exposição com espaços de saúde e beleza, cultural, EaD, jogos educativos, e contando ainda, com um rico espaço pedagógico com informações sobre o uso de tecnologias educacionais nos processo de ensino e aprendizagem.

A partir desse apanhado geral do que constituiu a 9a JORNATEC 2011, o que segue resgata em sua essência, discussões, comentários e formulações desenvolvidos durante os dois dias de encontro.

\section{Das conferências, palestras e mesa temática}

O núcleo de sentido do desenvolvimento da JORNATEC encontra solidez na constatação de que é preciso "enriquecer" a aprendizagem, partilhando pontos de vista sobre uma gama de questões relativas à educação. Cultivar um olhar e uma prática com objetivo de aliar formação técnica à formação humana, sem dúvida, representou o centro nodal da proposta do evento. Nesse sentido, considerar os contextos sociais e inovar em práticas educativas constituiuse no eixo norteador das construções discursivas dos palestrantes, visando um significativo esforço de consciência dos participantes envolvidos. Prova disso, deu-se na abertura do evento com a apresentação artística do Circoloko Alucinações, deixando o público, literalmente com "água na boca" sobre as possibilidades de sincronia entre corpo, mente, música e tecnologias visuais, ou seja, as mais variadas formas de se fazer educação.

Tais elementos fundamentaram com maior ou menor ênfase cada uma das falas dos profissionais convidados ao longo do encontro. Desse modo, iniciamos reconstituindo alguns aspectos relevantes do discurso proferido na conferência de abertura. Em Nada substitui um bom professor, António Nóvoa (Lisboa), de forma contundente, chamou a atenção dos profissionais a respeito dos cuidados aos modismos presentes na educação. Segundo ele, "modas são a pior maneira de pensar a educação", e como tal, constituem a causa, "dos maiores fracassos na educação". A crítica refere-se a "opção preguiçosa de planejar as aulas" uma vez que nada 
é evidente em educação, delegando ao professorado o desafio de educar quem não quer aprender. 0 conferencista atrela planejamento de sala de aula ao difícil trabalho sobre o conhecimento. 0 que isso significa? Significa que é preciso apropriarse do conhecimento criando formas de disseminá-lo, mas independentemente das tecnologias educacionais utilizadas, "nada substitui um bom professor". 0 apelo recai ao retorno do papel educador do professor que, de acordo com Nóvoa, se perdeu ao longo dos modismos a partir dos anos de 1980. Qual a relação com a gestão? 0 conferencista insiste de que é preciso "recusar todas as tendências que apontam a escola como um serviço e afirmá-la como uma instituição". Isso implica focar na aprendizagem, por meio da qual, se pode contribuir para uma nova identidade profissional. É nesse tripé que deve estar baseada a identidade do professor: aprendizagem, instituição escolar e sociedade.

Fundamentadas as bases, segundo as quais, é preciso pensar a relação educação e as redes de aprendizagem com ênfase ao papel do professor, a Jornada para Educadores, evidenciou, numa panorâmica geral, a práxis docente e o uso das redes sociais de aprendizagem. As palestras de Antônio Zuin (UFSCar) e Sérgio Abranches (UFPE) aprofundaram o debate a respeito de o porquê é importante discutir o papel do educador no século XXI e as necessidades de aprender a administrar múltiplas linguagens de aprendizagem. Diante das mudanças tecnológicas, "a educação, como fica?", questionou Abranches em sua fala. Sem dúvida, tornar uma aula mais cativante incorporando a cultura digital constitui-se como um desafio. Incorporar tecnologias móveis, a exemplo de celulares, lousa digital, netbooks nas salas de aula pressupõe escolas e profissionais preparados, tanto do ponto de vista pedagógico, quanto da gestão administrativa. Zuin e Abranches preocuparam-se em focar atenções à inclusão digital, tema de grande repercussão na mídia nacional.

No que se refere à Jornada para gestores, Frederic Michael Litto (SP) e Jucimara Roesler (SC), fizeram o público contrastar passado e presente, ou seja, criaram uma ambiência abordando a educação a distância e as redes e mídias sociais, respectivamente. As novas gerações desafiam o professor a planejar o processo de ensino e aprendizagem sem que este deixe de acompanhar a velocidade na produção e distribuição de conhecimento. Valorizando as possibilidades das tecnologias digitais, poder-se-ia dizer que ambos os palestrantes partilham da ideia de que a educação a distância representa mais do que uma modalidade de ensino, configurando-se sim, em aprendizagem. Na proposição de Roesler, é preciso pensar como os novos canais de comunicação digital, as redes sociais da Internet podem tornar mais eficiente $o$ aprendizado dos alunos. Valendo-se de uma panorâmica geral, a palestrante apresentou as redes sociais mais acessadas no Brasil e no mundo, indagando como tais ferramentas poderiam potencializar o trabalho didáticopedagógico. Litto e Roesler, em essência, deixaram aos gestores muitas interrogações e a difícil tarefa de pensar como promover a aprendizagem a partir da educação a distância, das redes e mídias sociais.

As palestras de Roberto Aparici (Espanha) e Nelson De Luca Pretto (BA), 
ambas direcionadas tanto aos gestores quanto aos educadores, preanunciaram a necessidade de se renovar o planejamento de sala de aula considerando as redes sociais. À medida que se expande o acesso ao celular, facebook, orkut, entre outras ferramentas, o professor tem ao seu alcance um grande leque de opções metodológicas. Mas estas constituem condição suficiente para que os alunos aprendam? De acordo com Aparici, não. Segundo ele, "o que está em jogo é a intencionalidade, o objetivo pedagógico associado". A crítica que persiste e merece nossa atenção diz respeito ao uso de novas tecnologias sem que se mude o ato de ensinar. Permanece, muitas vezes, inalterada a concepção de educação do professor, bem como persiste o uso do "novo" com caráter de um "velho" conceito de aprendizagem em que a colaboração, a interação e a construção coletiva só se efetivam em nível de discurso. Como bem lembra Pretto em sua fala, a escola ainda é "um espaço de conexões lineares" em um mundo que exige a desconstrução dessa linearidade. Estabelecer novas e outras conexões exige que as instituições escolares adaptem/mudem sua arquitetura, revendo também seus processos pedagógicos que, neste momento histórico, continuam a instigar apenas o trabalho individual, competitivo e mecanicista (BEHRENS, 2000).

0 que está em jogo, na perspectiva de Aparici e Pretto, é a qualidade do trabalho pedagógico realizado pelo professor. Voltase, assim, a importante ideia do valor do professor, como expressão e maximizador das possibilidades disponíveis via tecnologias da informação e comunicação (TIC's). Eis o caráter e a potencialidade da aprendizagem combinando as TIC's e a ação docente planejada.

Como vimos até o momento, a JORNATEC, constituiu-se num espaço de valorização do trabalho docente buscando inseri-lo aos novos contextos de aprendizagem. Frente às redes sociais, a discussão sobre a ética do professor faz-se necessária. Tendo presente tal preocupação, na Mesa Temática A ética no trabalho docente, com os professores Branca Jurema Ponce (SP) e Alípio Marcio Casali (SP), aprofundou-se o debate sobre as escolhas, as ações pedagógicas dos professores a respeito da formação de seus alunos. Sabemos que há "usos e abusos" da Internet, das redes sociais disponíveis, dos variados canais de comunicação. Estes, se utilizados de forma distorcida, equivocada, invadindo privacidade, desrespeitando "regras sociais" perdem seu caráter positivo, assumindo o efeito danoso e controverso aos objetivos centrais das redes de aprendizagem que é propiciar interação rompendo espaço/tempo, bem como um espaço democrático de construção de aprendizagens e busca de informações. Para tanto, discutir os princípios fundantes da ética na prática docente fornecerá bons elementos de conduta no trabalho dos professores, por meio das redes de aprendizagem.

Por fim, depois de dois dias de muita reflexão, a conferência de encerramento, 0 papel dos educadores na formação do projeto de vida dos educandos, proferida por Léo Fraiman (SP), cumpriu um belíssimo papel ao mostrar como o que é ensinado a um aluno tem um alcance muito maior do que é possível prever. Por isso, aumenta a responsabilidade do ato de educar, uma vez que, na visão de Fraiman, “o melhor educador do mundo não consegue 
fazer com que o aluno aprenda tudo". 0 palestrante imprimiu serenidade e seriedade numa discussão com graus de complexidade. De uma forma lúdica, deixou o recado: "Para doar algo, é preciso estar dotado de algo". A frase curta, mas com tamanhas implicações refere-se, em especial, à relação estabelecida em sala de aula. Como são planejadas as atividades de aprendizagem? Com emoção? Com significado? A partir de considerações da neurociência, Fraiman, preocupouse em frisar o quanto ainda é grande o "descompasso entre o que se espera e o que se encontra", reforçando o valor do planejamento didático-pedagógico. Para ele, precisamos incitar uma "ginástica mental" para que os alunos aprendam, pois "quanto maior o estímulo maior as conexões". Eis o desafio proposto pelo conferencista!

\section{Algumas considerações reflexivas}

Não são recentes as evidências de amadurecimento teórico-analítica das instituições educacionais. Muito além de uma formação focada somente no posto de trabalho de outrora, as relações de trabalho, fruto de uma série de mudanças no mercado de trabalho, refletem na atualidade, a necessidade de uma formação para além da técnica. Está em jogo aprender a conciliar formação técnica e formação humana. 0 que isso significa?

Segundo a perspectiva proposta na 9a JORNATEC, uma das vias seria pensar a respeito das possibilidades das redes de aprendizagem, uma vez que estamos vivendo o auge da crise do paradigma tradicional de educação. Aliás, nunca se falou tanto sobre a necessidade de mudar a dinâmica do ato de educar. Isso não quer dizer o abandono de conteúdos curriculares, mas, sobretudo, implica refletir sobre o que se tornou marcante ao longo da história da educação: uma aprendizagem memorística destituída de conteúdos afetivos, de diversidade de atividades e recursos didático-pedagógicos. Incorporar as redes e mídias sociais, potencializar a produção do saber considerando a educação a distância, administrar e não omitir os diversos acessos às informações, sem dúvida, desafiam os profissionais da educação mostrar aos alunos o quão concreto é o mundo no qual estão inseridos. Para os gestores, abre-se um campo fértil em que dotar o espaço educacional de outros acessos à informação implica, além de investimentos financeiros, acreditar que é preciso mudar o processo de ensino e aprendizagem e que há responsabilidades a esse respeito.

Concordando com a formulação de Tébar (2011, p. 143), no que se refere a "sociedade da mudança educativa" há de se ter presente que "essa nova realidade social exige uma análise do papel que a escola deve exercer, a fim de promover a educação total da pessoa". De acordo com Delacôte (1996, apud TÉBAR, 2011) são três os aspectos que se devem considerar quando se trata de pensar a melhoria na educação. 0 primeiro está relacionado ao maior domínio dos professores sobre os processos cognitivos e sociocognitivos da aprendizagem, sendo o segundo, relativo à criação de ambientes de aprendizagem interativos, desafiadores e cognitivamente eficazes. Por fim, o terceiro aspecto remete à organização das instituições e dos sistemas educacionais. Considerando a relevância dessa proposição, há de se pensar que o desafio na educação, dentre os vários elementos que poderiam 
ser mencionados, está em formar/educar articulando conteúdos curriculares, conteúdos relacionados às atitudes/valores a novas práticas didático-pedagógicas, sem perder de vista o intercâmbio com as redes e mídias sociais.

É oportuno registrar os inúmeros comentários ao desenvolvimento da JORNATEC, evidenciando o quão complexo é lidar com os aspectos comportamentais dos alunos e o quanto a Internet, o celular, o facebook entre outros, desestruturam a organização "engessada", o qual é conhecido o espaço educacional, mas que ainda assume forte representação e é sinônimo de "porto seguro" para muitos professores.

É fato que os computadores, as redes sociais, as mídias são fantásticas possibilidades de promoção de interação e aprendizagem, mas por si só, não modificam o indivíduo. É por isso, que na JORNATEC de 2011, a conferência de abertura primou por afirmar que Nada substitui um bom professor, bem como essa ideia tornou-se importante fio condutor no discurso da maioria dos palestrantes.

Por fim, a cada edição da JORNATEC atualizam-se discursos a respeito da necessidade de valorização e desenvolvimento de ações didáticopedagógicas considerando novos contextos sociais nos quais se presenciam mudanças. A experiência concretizada a partir da nona edição do evento permite dizer que em educação ainda há muito a se dizer sobre: formação, aprendizagem, professores, gestão educacional, e pensando nessa perspectiva, aguardaremos a $10^{\mathrm{a}}$ JORNATEC.

\section{REFERÊNCIAS}

BEHRENS, M. A. Projetos de aprendizagem colaborativa num paradigma emergente. In: MORAN, J. M. et al. Novas tecnologias e mediação pedagógica. Campinas, SP: Papirus, 2000.

TÉBAR, L. 0 perfil do professor mediador: pedagogia da mediação. São Paulo: Editora Senac São Paulo, 2011.

\section{Adriana Cláudia Turmina}

Mestre e Doutora em Educação pela Universidade Federal de Santa Catarina (2005). Pesquisadora do Grupo de Estudos sobre Política Educacional e Trabalho GEPETO da UFSC e compõe a equipe de capacitação docente do Senac/SC.

Endereço eletrônico: adrianact@sc.senac.br

Currículo lattes: http://buscatextual.cnpq.br/buscatextual/visualizacv.do?id=K4795314D8 